\title{
La Antropología y la Gerontología Social
}

\author{
Michel Romieux
}

El mundo cambia a una velocidad sorprendente, siendo afectados en forma directa nuestras vidas, entorno familiar y laboral. Para algunos, los cambios han sido violentos; otros no han percibido la transformación del medio, pero no por eso han escapado de ella. Nuestras relaciones sociales ya no están organizadas ni pautadas como las de nuestros padres; vivimos en un mundo diferente de aquel que nos vio nacer. Los muy jóvenes difícilmente imaginan una sociedad con precarias y lentas comunicaciones, alejada de la TV. de la radio y la computación, con pocos vehículos y más escasos aviones, en la que la mayor distracción consistía en la vida familiar y el trabajo. Numerosas familias creen no poder soportar la existencia sin los electrodomésticos y no recuerdan que hubo un tiempo en los hogares en que toda actividad respondía a la fuerza y habilidad manual. El impacto del cambio tecnológico y el consecuente cambio social abarcan las manifestaciones culturales de una manera $u$ otra.

La antropología, por el mismo carácter del objeto de su estudio, el hombre, es una de las ciencias más afectadas. La última gran guerra no dejó lugar en el orbe que no fuera tocádo. La tecnología llegó a todas partes, el urbanismo se difundió definitivamente, los sistemas de producción fabril y la organización burocrática se expandieron. Las ideas políticas modernas impregnaron a los pueblos. Los conocimientos médicos, la ayuda internacional, las campañas de salubridad, una mejor alimentación, prolongan nuestras vidas modificando la demografía.

Aquellos grupos en los que tradicionalmente enfocábamos nuestros estudios, "nuestros contemporáneos primitivos", como los llamó Murdock, fueron conquistados por el encanto de los motores y las drogas maravillosas, adquiriendo los conflictos de nuestra civilización. Nos encontramos en situación similar a la que se dio en algún momento del neolítico, en el que una multitud de culturas compartieron una 
misma tecnología. Igualmente nosotros usamos técnicas, organizaciones. símbolos económicos, manteniendo difícilmente nuestras identidades culturales, que a diferencia de otras épocas son afectadas por la comunicación.

Los antropólogos buscamos en nosotros mismos los temas fundamentales que no se encuentran ya simplificados en el llamado "primitivo", que ahora es urbano y con el cual compartimos los mismos problemas.

El origen de las estructuras sociales parte de la familia, expresada en los sistemas de parentesco de las sociedades elementales. El sistema de parentesco reúne en ese estadio todas las funciones posibles de las relaciones entre individuos en sociedades humanas. Un sistema así, que acumula pautas, afectos, obligaciones, derechos, intercambio de bienes y personas, y que además es un aparato de seguridad para individuos y grupos, constituye "la prestación total" (MAuss, p. 63) mayor que pueda existir. Una institución de esta amplitud sufre un desgaste que lleva a su fraccionamiento en múltiples pequeñas prestaciones totales.

Se dice que las culturas y los sistemas sociales son anantrópicos por excelencia, pero esto es en apariencia. La entropía se ve desplaza$\mathrm{da}$ al fraccionamiento del sistema y se expresa en subsistemas con funciones parciales. Vemos aparecer las instituciones religiosas, guerreras, económicas, políticas, etc., que restan actividades e individuos a la primitiva forma de relación aportada por esa "prestación total" que es el parentesco.

De este largo proceso, que no es otro que la historia de la humanidad y las culturas hasta llegar a nuestros días, el sistema de parentesco elemental va perdiendo fuerza en sus prescripciones, dando paso al individuo moderno con su corta familia nuclear y sus vagos parentescos que en generaciones no muy lejanas casi todos poseíamos. La industria moderna, la fragmentación del trabajo, la burocratización de las relaciones. la pérdida de las fronteras de las clases sociales, la lenta erosión de los roles, fueron los complementos de la formación de ese fantasma, el individuo solitario que ahora nos atormenta.

No deseo defender el antiguo régimen, sólo enmarcar nuestro problema, el ciclo vital de ese nuevo espécimen de hombre, que aparentemente flota en la sociedad moderna sin roles claros y con relaciones débiles y ocasionales. Rodeado de instituciones que reemplazan ampliamente a la familia: el control de la natalidad, la procreación artificial, la popularización de la adopción, el jardín infantil, la escuela, las instituciones educativas, la fábrica, la oficina, la tarjeta de crédito, el periódico, el teléfono, la TV, el restaurante, el hotel y el hospital, los refugios para enfermos e incapacitados, solitarios y ancianos y las UTI, verdaderas salas de la muerte, nuestra cultura nos entrega los elementos que permiten vivir en soledad.

La familia, la amistad, las actitudes creadoras de vínculos, ya no son el paso indispensable a la vida. Se hace evidente que cada día nos 
aproximamos a una nueva estratificación social, de estamentos iniciáticos por calificación burocrática y próximamente por operación computarizada e irreversible, ante la infalibilidad mítica de lo automático. Estas clases: los niños, los adolescentes, los jóvenes, los adultos, los adultos mayores, los ancianos y los muertos, por fin lograrán una independencia monstruosa cuyo juego social sólo sería posible en el ordenador electrónico de la ya obsoleta estructura social.

Pero regresemos al principio. El objeto del esfuerzo de los hombres, sin olvidar la base biológica e instintiva del comportamiento, es la búsqueda de la seguridad que da la relación recíproca entre personas confiables. Es decir, del intercambio codificado en un lenguaje de reciprocidades, respeto, roles, status y estratificaciones en los grupos sociales. Este código en nuestra sociedad occidental u occidentalizada está expresado en relaciones de producción, en intercambio de bienes económicos a través de prestaciones laborales y contraprestaciones monetarias, en fin por medio de dinero y sus simbolos de prestigio. Relaciones descritas magistralmente por Marx y enriquecidas por Veblem y tantos otros. Estratificaciones sociales que se expresan en poder económico, que a su vez se transforma en político. Pero esta trama se continúa sosteniendo teóricamente sobre el antiguo sistema de parentesco que proporciona los canales de la herencia de la propiedad. Nuestro problema se visualiza en el momento en el que comprendemos la debilidad de este soporte básico y antiguo ya desaparecido en la mayor parte de nuestra sociedad, quebrando la continuidad entre las generaciones. Quedando sólo la estratificación económica como expresión del código de reciprocidades y que en adelante se expresará en un monetarismo simplificador.

A pesar de la variabilidad y la abundancia de los intercambios económicos, de la infinita división y fragmentación del trabajo y de la tecnología que caracteriza nuestra época, estas relaciones son de una extremada pobreza social, al ser incapaces de producir la estabilidad necesaria al sentimiento de seguridad durante el ciclo vital de los individuos. Desaparecida la obligatoriedad de las relaciones de parentesco, el individuo sufre un doble desarraigo: pierde su territorialidad y se hace ubicuo en sus status, surgiendo una estratificación referida a la apariencia que dan la edad, el sexo, la ocupación y el dinero.

La confusa lucha de las feministas condujo a la igualdad teórica de los sexos, pero rompió las relaciones de complementariedad, dejándola al azar de los encuentros o, mejor, de los desencuentros. Planteó la justa equivalencia ante el trabajo idéntico, pero esa lucha justificada ante la opresión familiar decimonónica fue igualmente causante de una nueva segregación ya no de sexos, sino de edades marginadas.

La nueva familia no debe tener hijos y no tiene ancianos. No tiene ascendientes y no desea descendientes. Es sólo una pareja de cohabitantes igualitarios, ya casi no importa si son o no del mismo sexo. No existe la filiación, ni tampoco la alianza y se busca suprimir la consan- 
guinidad. La pareja sólo cumple una función sexual y da una débil protección a la soledad del adulto laborante y a su angustia productiva.

El niño, inevitable, pasa a ser un juguete que se deja durante la mayor parte del tiempo en la guardería infantil. Y el abuelo, el antiguo pater familiae, la vieja madre, son abandonados a la llamada "seguridad social". Aparece una nueva forma de marginación en nuestra temible sociedad, una nueva lucha de clases: niños, adultos, ancianos, luchando por el espacio y la vida dentro de su propia familia. Las instituciones que creamos para solucionar este abrumador conflicto reafirman la separación de las edades, guarderias para niños. lugares de trabajo y asilos para ancianos.

Revisemos brevemente la evolución de la familia occidental en los tiempos modernos, su adaptación, su transformación y el medio social y económico que la desarticuló. Hasta la Primera Guerra Mundial, la responsabilidad económica y la autoridad dentro del sistenıa familiar fueron parte del rol que le correspondia al hombre. Se practicaba un neolocalismo, pero la dote y la herencia mantenian las relaciones del patrilinaje, la mujer y los niños ocupaban un lugar de subordinación y, en teoría, no tenían responsabilidades económicas. La guerra lanzó a la mujer fuera de su hogar, atrayéndola a la fábrica, necesitada de mano de obra para esta primera gran guerra industrial. La mujer fue adquiriendo una pequeña libertad económica. quedando con roles contradictorios: trabajadora fuera del hogar, y madre-esposa, dentro del hogar; libre fuera de casa, sometida dentro de casa. La contradicción era demasiado fuerte y en consecuencia afectó la estabilidad de la familia. Los derechos y deberes que equilibraban las prestaciones dentro de la familia, correspondientes a la terminología del parentesco, dejaron de ser un código prescriptivo de conductas, para convertirse en un vago calificativo de los individuos (padre, madre, hijo, etc.), surgiendo una nueva manera de vincularse que imita el ambiente que rodea la familia. La nueva relación se establece entre productores y consumidores, el rol del que aporta el producto-dinero es independiente de la estructura familiar, el consumidor se defiende recurriendo al vínculo del parentesco, ya desprestigiado. En este sistema el hijo, las mujeres y los hombres no productivos pasan a depender de aquel o aquellos que aportan bienes sin dar una contraprestación considerada equivalente. Los conceptos del rendimiento fabril y burocrático penetran en el hogar y desarticulan las antiguas obligaciones, fidelidades y privilegios. El niño, el joven y el anciano no caben dentro de este esquema. A través de lo que nos ha entregado la etnografía, la familia tiene una gran flexibilidad y grandes posibilidades de adaptación, siempre y cuando esté encuadrada en un sistema mayor, el parentesco, que la une a la sociedad y que, en muchos casos, es la sociedad. Nuestro sistema de parentesco no pasa de ser un romántico recuerdo cuyo contenido es sólo nominativo y obedece a una vaga necesidad de identidad y pertenencia, de remanso al deseo y a la transitoriedad de los afectos. 
Lo anterior no significa que no exista la familia en Occidente, sólo indico la precariedad de la misma y resalto los esfuerzos que los individuos hacen para conservar sus vínculos. El núcleo fuerte de la familia se desplazó de la autoridad-producción del padre y jefe de linaje, a la pareja genitora en producción económica, cuyo empleo del tiempo es en su mayoría absorbido desde la niñez (escuela), por el trabajo tiempo completo fuera del hogar; sus relaciones y sus pares se encuentran en el círculo laboral, sus contactos familiares y aún los filiales, paternales y matrimoniales escasos, reducidos a breves encuentros en el descanso.

El patrilinaje roto por el neolocalismo y el individualismo deja a los mayores no productivos abandonados a su suerte. Después de una vida de trabajo fuera del hogar, no saben emplear su tiempo en él, ni reorganizar sus relaciones que anteriormente estaban centradas en su actividad económica. Los contactos con los hijos adultos son difíciles debido a su falta de tiempo y al recuerdo de una infancia sin afecto, los niños viven su propio mundo en la escuela que igualmente copa su vida.

Nos encontramos pues, que sin que nadie lo desee, sin ninguna rebeld ía ni rechazo, la familia se compone de miembros de clases de edad incomunicados por sus roles y funciones reales, ordenadas desde fuera del hogar. Estas clases de edad tienden a consolidarse en roles propios para llenar sus necesidades afectivas, rompiendo definitivamente la unidad de la familia y creando una verdadera contracultura $(*)$ de cohortes sin continuidad, incomunicadas en un sinsentido en el que se niega el transcurso del tiempo, la complejidad de la vida y la riqueza de la multiplicidad de los contactos entre edades. Las series ancianos, adulto, joven, niño; abuelo, padre, hijo; la afectuosa relación abuela-nieta, son generalmente parte de la nostalgia del pasado. No existe en nuestra cultura un lugar donde individuos de sexo y edades diferentes puedan gozar de sus mutuas oposiciones, provocadoras de intercambios, lazos y afectos.

A diferencia del niño y el joven que tienen un tránsito hacia la adultez, los condenados por Bismarck a abandonar su trabajo son enfrentados a un mundo sinrazón: la jubilación. Partiendo de los prejuicios judeocristianos que conciben el trabajo como un castigo, nuestra vida se organiza en una dicotomía de trabajo-descanso. La responsabilidad y el compromiso familiar se expresan en la asiduidad al trabajo productivo (dinero), el descanso es el premio merecido a la labor realizada; el descanso o la inactividad no justificada son una irresponsabilidad (financiera) hacia la familia. El trabajo es la expresión del amor o, mejor, el dinero es amor.

\footnotetext{
* Tentativamente definimos contracultura al conjunto de normas de un grupo minoritario incomunicado por su misma normatividad con la sociedad dominante de la que profita, pero simultáneamente rechaza.
} 
Aquel que no trabaja sufre una doble carencia: no sabe expresar sus sentimientos familiares en la debida forma y pierde el respeto por sí mismo, debiendo ser rechazado por él y los suyos. Aquel que no labora o cuya actividad no es medible por el código monetario, adquiere mala conciencia; su descanso no es merecido y debe rechazar el afecto familiar. La jubilación en la mayoría de los casos es una condena que margina del trabajo y que, por lo tanto, justifica el desamor de los suyos. Es un nuevo tormento para Sísifo sustraerle su roca y dejarle el deseo de un deber imposible.

Conocemos lo injustificado de estos prejuicios, nadie cree en ellos, nadie estaría dispuesto a condenar a un anciano al ostracismo por el solo hecho de no trabajar y de tener un renta reducida. Pero todos, la víctima inclusive, actuamos como si lo condenáramos. Al tomar conciencia de la injusticia, reaccionamos, encontrándonos ante la realidad de nuestras viviendas, que nosotros no construimos, en las que una persona mayor no tiene cabida, o en las cuales tampoco cabemos nosotros.

Cuando no son nuestros prejuicios, son realidades físicas de un mundo en el cual no hay sitio para familias plurigeneracionales. Eso que en el lenguaje de la marginalidad en Chile llaman "allegado", que es aquel que por algún misterioso proceso alquimista pasa sin transición de pariente a extraño (el joven que se casa, la hija madre soltera, el adulto sin trabajo y el viejo improductivo), y que debe irse lo más pronto posible.

Podemos ver que el fenómeno es mucho más profundo y complejo de lo que suponiamos al comienzo, estando en la estructura de nuestras normas y en su contradicción encubierta con la realidad.

Esa hermosa secuencia que presenta Erik H. Erikson sobre la acción recíproca de las etapas de la vida:

(a) niñez: confianza vs. desconfianza. Esperanza.

(b) primera infancia: autonomía vs. vergüenza. Voluntad.

(c) edad de jugar: iniciativa vs. culpa. Propósito.

(d) edad escolar: laboriosidad vs. inferioridad. Competencia.

(e) adolescencia: identidad vs. confusión de identidades. Fidelidad.

(f) adultez joven: intimidad vs. aislamiento. Amor.

(g) madurez: procreación vs. ensimismamiento. Cuidado y solicitud.

(h) vejez: integridad vs. desesperación, disgusto. Sabiduría, toma verdadero sentido en el momento en que comprendemos que cada período de la vida es una representación que el individuo debe actuar para un público formado por las personas vinculadas a él y en otras etapas de la vida. Es el niño o el joven en su actuar los que crean por diferenciación al adulto o al anciano y viceversa. Es un juego de comunicaciones entre las edades, lo que viene a dar un sentido y una continuidad a la vida.

Este desarrollo que va de la niñez a la vejez, pasando por una ordenada sucesión de objetivos, es para nosotros un sueño no realizado. La 
edad escolar empieza casi en el nacimiento; la adolescencia, época de la afirmación de la identidad, se confunde con la búsqueda del amor. sin la posibilidad de la intimidad, surgiendo en muchos casos la procreación sin el cuidado y la solicitud. Tres épocas de la vida, que deberian estar claramente definidas, se reagrupan en un bloque indiferenciado durante la existencia de nuestros jóvenes. Adolescencia, juventud y madurez se unen dentro del mismo compromiso.

La duración de la preparación de la juventud, las exigencias técnicas y académicas, prolongan la adolescencia hasta la madurez, entrando en ella con una carga de fracasos creados por la imposibilidad de una independencia, biológicamente justificada, pero económicamente imposible. Los jóvenes logran su difícil madurez a los treinta años, iniciando su vida productiva sobre el fracaso de sus relaciones afectivas. Establecidos a pesar de todo en sus roles de adultos y miembros responsables de sus familias, se van aproximado a su marginación por la amenaza de una nueva tecnología y la prematura jubilación. El éxito económico o profesional no es protección suficiente para este temprano final. Se ingresa a la vejez contemporánea en la plenitud de las fuerzas, a ese período de la vida que en nuestra sociedad ya no tiene ningún rol.

Estamos muy lejos del mundo etnográfico al que por interés y oficio nos apegamos aquellos que nos interesamos en la Antropología. Los ejemplos llenan volúmenes de monografías magistrales sobre ciclos de vida en que los hombres desde su nacimiento hasta después de su muerte son actores y centros de la actividad comunitaria. Recordemos ese maravilloso ejemplo que se encuentra en las películas de Jean Rouch: "Funerailles a Bongo, Le vieil Anaï" y la serie de los "Sigui" realizados en colaboración con Germaine Dieterlen, en los que podemos apreciar cómo la vida se encadena en un mito que se inicia con el primer hombre de este pueblo de filósofos que son los Dogón, que se continúa en un ritual repetido cada sesenta años, lapso de la vida de un hombre. Cuenta Rouch: "... cuando se efectuó el Sigui en Bongo en 1969, el decano que presidia la ceremonia, Anaï Dolo, asistía a su tercer sigui. Tenía ciento veinte años. Un año más tarde fuimos a verlo a la entrada de su casa, estaba sentado sobre tablas de acacia; no salía jamás de su encierro, estaba siempre a la misma temperatura. Había reencontrado la placenta en el vientre de su madre. Todos aquellos que entraban en su casa lo saludaban y le decían a qué habían venido" (FAlChignoni, p. 51). El respeto ejemplar al anciano Anaï Dolo, que en vida fue su propio antepasado y a su muerte presidió su propio funeral y la teatralización de su propio recuerdo, el cual se convierte en mito, es la culminación ideal de un ciclo vital siempre repetido. Ejemplos como ese, tan lejano, encontramos en nuestra práctica, ya sea en un poblado como Peine, o en las rucas mapuches de Cholchol, donde reinan los ancianos como jefes respetados en sus casas y vecindario. En estos grupos etnográficos existen los pobres; raramente los solitarios. 
Estamos lejos de esos mundos. En la sociedad urbana e industrial surge esa contracultura, la que se asemeja a una legión romana que marcha del nacimiento a la muerte en formaciones cerradas e incomunicadas de cohortes que arrastran cada una un pasado diferente y misterioso para las otras, con las que comparte solamente el ritmo del paso hacia la muerte que todas niegan a coro.

En contra de esta situación voluntariamente exagerada, pero no lejana de la realidad y observable en muchos casos en nuestro vecindario ciudadano y fabril, es donde la Antropología debe aplicar sus conocimientos buscando soluciones.

La Antropología Aplicada no debe seguir refugiada en la ayuda "aculturalista" a grupos seudoprimitivos, ni ser el dócil instrumento de consulta de asociaciones caritativas, con finalidades parciales y no muy claras. Nuestra parcela de conocimiento por especializada que sea está referida a la cultura y a su sociedad como un sistema sólo comprensible en su totalidad, que limita con la variabilidad cultural de otro conjunto igualmente definible.

El impacto del urbanismo y de la tecnología llegó a todos los lugares del mundo; ya no quedan regiones-refugio. Las etnicidades están en un mal pie. Todos sufrimos el mismo mal expresado en mil lenguas y culturas: somos demasiados y nuestro pasado no entrega respuestas a nuestros problemas. Si la Antropología Social o Cultural pretende algún lugar dentro de las ciencias sociales, que no sea el histórico, tiene que actuar. ¿Y actuar cómo? Sobre nuestra propia y fragmentaria familia, sobre nuestro vecino. Vecino que pasó de ser nuestro auditorio a ser el único objeto de nuestro estudio y nuestra acción. Recordemos que la gente de nuestra ciudad, nuestros compañeros de trabajo, son con justo título representantes del Homo Sapiens en la misma calidad que el más alejado de los primitivos.

El ciclo vital de los individuos no transcurre a la misma velocidad en diversas culturas, ni en todas las épocas. La historia ha variado la duración de los periodos de nuestras vidas. La madurez, la vejez y la ancianidad vienen más pronto y duran más. Atrapados por una tecnología que se perfecciona suprimiendo y simplificando el trabajo de los operarios, afectando las relaciones de producción, sobran manos, sobran hombres. Vivimos en un momento en que los conocimientos, las técnicas, las artes, se hacen obsoletas en breve tiempo. En fin, nuestras relaciones con el trabajo, la familia y la sociedad son inestables.

Ante los anteriores problemas, la sociedad ha reaccionado y tratado de reemplazar las partes rotas de nuestro sistema social. Basados en la antigua tradición cristiana, han surgido todo tipo de instituciones de caridad para suplir las falencias de las relaciones sociales y de la producción. Posteriormente, la caridad ha ido cediendo terreno ante las instituciones públicas que dan servicios más amplios y constantes al no depender de donaciones. 
Estas instituciones obedecen a un patrón común, hijo de la necesidad y la tradición: el hospicio, origen de una larga serie de establecimientos-refugio, para niños, enfermos y ancianos. Sin importar la época, ni los adelantos teóricos y técnicos, estas instituciones hospitalarias son manejadas por burocracias que imponen sus reglas y que pasan a constituir instituciones totales, en las que prima la comodidad del asistente en desmedro de la del asistido. La primera consecuencia es ignorar la velocidad del envejecimiento en los diferentes individuos.

Surgen una serie de teorias y modelos a nivel científico y popular en relación a los procesos del envejecimiento. El primero y más popular es el concepto de la decadencia de la capacidad, inteligencia y su marginación. Cierto es que la edad produce cambios en los individuos: la fluidez de adaptación, la capacidad de combinación, la orientación en nuevas situaciones (fluid intelligence) disminuyen, pero se da un incremento en los conocimientos generales, el saber basado en la experiencia, el caudal de vocabulario y la comprensión del lenguaje (cristallized intelligence). lgualmente hay un factor de velocidad en las respuestas y se deben tener en cuenta las dotes iniciales, la formación escolar, la historia individual y, por último, el ambiente que rodea a la persona. Es frecuente que se confunda la decadencia con la incapacidad que siempre hubo, o con la intensificación de trastornos permanentes durante la vida del sujeto (Lehr).

Entre los conceptos teóricos sobre el envejecimiento se destaca la teoría de la actividad y la de la desvinculación. Sus nombres son un resumen de su contenido. La teoría de la actividad parte de la premisa de que la felicidad está unida a la acción y utilidad hacia los demás. En cuanto a la desvinculación, es la tesis que sostiene la tendencia del anciano al aislamiento social y a la reducción de sus intereses. En general, todas las investigaciones empíricas llevan a criticar la desvinculación y favorecen la actividad como un camino aconsejable para los senescentes.

Nuestro punto de vista difiere un tanto. Durante el transcurso de su vida, la mayoria de los individuos varían con respecto a ciertas actitudes e intereses, pasando por períodos de duda y desinterés para regresar a nuevas actividades y, en casos, a nuevos afectos. El problema para el antropólogo sigue siendo el de la desvinculación e inactividad involuntaria, la falta de espacios para el encuentro entre generaciones; espacios a nivel de las actitudes entre diversas edades, que puedan desarrollarse en un marco ecológico apropiado.

No podemos predecir cuál será el destino de la familia y el parentesco, pero sí podemos asegurar que el ser humano continuará necesitando de la compañía de otros. No vamos a dejar de ser animales sociales y seguiremos buscando y perdiendo afectos, tratando de comunicarnos y luchando contra la soledad.

Nuestro deber, aunque no sea el del científico puro, es el de educar a la sociedad, creando las condiciones para que se abran formas de relación entre las diversas edades y condiciones humanas. La futura 
organización familiar y afectiva tiende a transformarse. Pensamos que será de una mayor variedad siguiendo la entropia natural; por lo tanto, para que esta variedad de formas aparezcan y convivan, debemos esforzarnos por luchar contra todo tipo de marginación, contra todo prejuicio, contra todo estigma social, más aún si hacen referencia a nuestros padres y abuelos. La Antropología no puede concebir una Gerontología social separándola del fenómeno familiar y de la sociedad total.

Es preocupante la tendencia a crear instituciones para "la tercera edad", "los años dorados", etc., en las cuales. con la idea de ayudar a los ancianos, se los reúne en rebaños segregados. Es comprensible la buena intención de estos esfuerzos, pero debe evitarse la separación por edades. Se debe permitir a aquellos que pueden continuar con sus actividades habituales, ejerzan su capacidad y desarrollen sus intereses estando incorporados a la sociedad. Igualmente, permitir el aislamiento de los que así lo deseen. Se dirá que el costo de un sistema tan variable e individualizado lo convierte en utopía, olvidándose que las personas mayores no son inútiles, pudiendo en múltiples casos administrarse y ayudarse mutuamente.

El anciano debe reencontrar un rol de importancia dentro de nuestra sociedad, reintegrándose a la producción y a la vida. Es la única forma como podemos soportar el envejecimiento de la población. Esto significa reorientar las relaciones de producción, dando una mayor flexibilidad al empleo del tiempo de los que trabajan, modificar los criterios normativos de la selección de personal; utilizar la nueva tecnología producto de la autonomia de las pequeñas herramientas, la miniaturización, la electrónica y la informática que sumadas a la riqueza de la comunicación permiten la ubicuidad del lugar de trabajo. En resumen, técnicamente estamos capacitados para integrar a todas las edades a cualquier labor. Podemos humanizar el trabajo convirtiénd olo en lo que en realidad debe ser. El juego magnífico de la vida del cual nadie debería estar excluido.

Vemos los inicios de un cambio de mentalidad con respecto a la problemática de la edad mayor. Sólo falta aplicar aquello que sabemos sobre nosotros mismos y es en este punto donde la Antropología debe tener un rol fundamental.

\section{BIBLIOGRAFÍA}

Dominguez, Oscar. "Vejez y envejecimiento". Cuadernos del Departamento de Salud Pública. División Ciencias Médicas Sur. U. de Chile, Santiago, 1985.

Erikson, Erik H. La adultez, México, F.C.E., 1986.

Falchignoni, Enrico. Jean Rouch, une rétrospective. Paris. Ministere des Affaires Etrangeres, 1981.

Lehr, Ursula. Psicologia de la senectud, Barcelona, Ed. Herder, 1987. 
Lévi-Strauss, Claude. Tristes Trópicos, Buenos Aires, Ed. Universitaria, 2a Edición, 1973.

Lévi-Strauss, Claude. Les structures élémentaires de la parenté, Paris, Presses Universitaires de France, 1949.

Mauss, Marcel. Sociologia y Antropologia, Madrid, Ed. Tecnos S.A., 1971.

Murdock, George P. Nuestros contemporáneos primitivos, México, Fondo de Cultura Económica, 1956.

Roa, Armando. "Las edades en la vida y el sentido de la madurez avanzada", Revista de Psiquiatría Clínica, Santiago, vol. XXIV, No 1, 1981.

Van Gennep, Arnold. The Rites of Passage. The University of Chicago Press, 1966. 